\title{
Assessment of Interleukin 1- $\beta$ in Controlled and Uncontrolled Type 2 Diabetic Patients
}

\author{
Mohamad S. Hamed, Enas M. Sabry, Bassem M. Mostafa
}

Department of Internal Medicine, Endocrinology and Metabolism, Ain Shams University Hospital, Cairo 11566, Egypt

*Corresponding author: Bassem M. Mostafa, Mobile: (+20)01144322070, E-Mail: Basemmurad44@med.asu.edu.eg

\begin{abstract}
Background: Type 2 diabetes has been identified as an immune-mediated disease characterised by poor insulin signaling and selective death of insulin-producing cells, with cytokines playing a key role. Disturbance of the antiinflammatory response could be a key component of the type 2 diabetes-causing chronic inflammation. The cytokine family interleukin 1 (IL-1) plays a key function in endocrinology and the regulation of inflammatory stress responses. Objective: The aim of this work is to assess the role of interleukin $1 \beta$, in patients with type 2 diabetes mellitus (controlled and uncontrolled) compared to healthy individuals.

Patients and Methods: A case control study was conducted on 80 adults, ranging from 25-60 year old, attending the endocrine or internal medicine clinic in Ain Shams University Hospital. They were divided into 3 groups :Group (1): 30 controlled type 2 diabetic patients on oral hypoglycemic. Group (2): 30 recently uncontrolled type 2 diabetic patients over the last 6 months, on oral hypoglycemic. Group (3): 20 healthy individuals.

Results: Serum IL- $1 \beta$ was significantly increased in recently uncontrolled diabetics than controlled diabetics and normal subjects. Serum IL-1 $\beta$ was positively correlated with fasting blood sugar (FBS), 2 hours post prandial ( 2 hrs PP), glycosylated Hemoglobin (HBA1C), triglycerides (TG) and HOMA IR and there was a negative correlation with high density lipoproteins (HDL).

Conclusion: The significant difference in the level of interleukin $1 \beta$ among the studied groups highlights an implication of interleukin $1 \beta$ in the pathogenesis of type 2 diabetic patients.
\end{abstract}

Keywords: Cytokines, Diabetes mellitus, Inteleukin1 $\beta$.

\section{INTRODUCTION}

Cytokines are a broad and diversified family of tiny cell signaling protein molecules. Interleukins and interferons, for example, are immunomodulating agents. Interleukin 1 (IL-1), Interleukin 6 (IL-6) and Tumor Necrosis Factor (TNF- $\alpha$ ) are produced by virtually all nucleated cells, particularly endothelial, epithelial, and macrophage cells ${ }^{(\mathbf{1})}$.

The interleukin 1 (IL-1) family plays a critical role in immunological and inflammatory response control. It controls the fundamental metabolic rate, blood glucose levels, and blood pressure, among other things. It also reduces insulin release and causes apoptosis in cells, resulting in type 2 diabetes. Polymorphisms in the interleukin 1 (IL-1) gene are type 2 diabetes susceptibility indicators in several populations ${ }^{(2)}$.

Interleukin 1 (IL-1) is a family of pro-inflammatory cytokines that includes interleukin 1 alpha (IL-1) and interleukin 1 beta (IL-1), as well as an anti-inflammatory drug called interleukin 1 receptor antagonist (IL-1Ra or IL-1RN) ${ }^{(3)}$.

Interleukin 1 beta (IL-1 $\beta$ ) is an inflammatory response regulator that is produced in response to infection, damage, and antigenic exposure. It's involved in autoimmune disorders including rheumatoid arthritis, inflammatory bowel disease, and type 1 diabetes, as well as diseases like atherosclerosis, chronic heart failure, and type 2 diabetes that are linked to the metabolic syndrome (4).

This article is an open access article distributed under the terms and conditions of the Creative Commons Attribution (CC BY-SA) license (http://creativecommons.org/licenses/by/4.0/)
Interleukin 1 beta (IL-1 $\beta$ ) has been a known mediator of beta-cell dysfunction and death and is potentiated by Tumor Necrosis Factor (TNF- $\alpha$ ) and Interferon Gamma (IFN-g), both of which are present at high levels under conditions of insulin resistance. Indeed, beta-cells are uniquely susceptible to interleukin 1 beta's effects as they express higher levels of interleukin 1 receptors (IL-1R1) than any other cell type in the body ${ }^{(5)}$. And their subsequent activation resulting in direct promotion of apoptosis, as well as the inhibition of insulin signaling, which is critical for optimal beta-cell function ${ }^{(6)}$. In addition, interleukin 1 beta (IL-1 $\beta$ ) signaling results in the production of pro-inflammatory mediators that act in a feed-forward autocrine/paracrine manner in beta-cells and local innate immune cells to amplify these effects ${ }^{(7)}$.

\section{AIM OF THE WORK}

The aim of this work is to assess the role of interleukin $1 \beta$, in patients with type 2 diabetes mellitus (controlled and uncontrolled) compared to healthy individuals.

\section{PATIENTS AND METHODS}

A case control study was conducted on patients attending the endocrine clinic at Ain-Shams University Hospital from November 2014 till November 2016 on eighty (80) subjects; their age ranged from 40 to 60 years. The subjects were divided into 3 groups: Group (1) 30 recently uncontrolled type 2 diabetic patients on sulphonylureas over last 6 months their FBS>130, 2 hrs pp $>180$, HBA1C $\geq 7$, Group (2): 30 controlled type 2 
diabetic patients on sulphonylureas over last 6 months their FBS<130, 2 hrs pp<180, HBA1C<7, Group (3): 20 healthy individuals $\mathrm{FBS}<100$, 2hrs $\mathrm{PP}<140$, HBA1C $<5.7$.

Exclusion Criteria: included all patients with chronic liver or renal disease, patients with any organ failure, malignancy or evidence of inflammatory or autoimmune diseases and patients kept on metformin and thiazolidinediones.

All patients were subjected to full medical history emphasizing on age, onset and duration of diabetes, thorough clinical examination including body mass index (BMI) measurement.

Laboratory studies: included fasting, two hours postprandial blood glucose level, glycated hemoglobin ( $\mathrm{Hb} \mathrm{A} 1 \mathrm{C}$ ), lipid profile including total cholesterol, triglycerides, low density lipoproteins, high density lipoproteins, fasting insulin, HOMA IR and serum interleukin-1 beta.

\section{Ethical approval:}

The study was registered and approved by local institutional committee of Ain Shams University Hospital and all procedures were in accordance with standards of 1964 Helsinki Declaration and its later amendments ethical standards. Informed consent was obtained from each participant included in the study.

\section{Statistical analysis}

After the collection of data, revision and tabulation; analysis was performed using Predictive Analytics Soft Ware (PASW) version 18. Quantitative parametric data were expressed as mean \pm SD. Qualitative data were expressed as number and percent of total. Comparative analysis was done using one-way ANOVA and Chi square tests for quantitative and qualitative data respectively. Correlations were done with Pearson's correlation coefficient. $\mathrm{P}$ value less than 0.05 was considered significant.

\section{RESULTS}

On comparing demographic, clinical and laboratory data among the different studied groups there was a significant difference as regards BMI, fasting blood sugar, 2 hours post prandial blood sugar, lipid profile, fasting insulin and HOMAIR between group of uncontrolled diabetic patients and controlled diabetic patients (Table 1).

Table (1): Comparison of demographic, clinical and laboratory data among the studied groups

\begin{tabular}{|l|c|c|c|c|}
\hline & $\begin{array}{c}\text { Recently uncontrolled } \\
\text { diabetics } \\
\text { (Group 1) }\end{array}$ & $\begin{array}{c}\text { Controlled } \\
\text { diabetics } \\
\text { (Group 2) }\end{array}$ & $\begin{array}{c}\text { Control } \\
\text { (Group 3) }\end{array}$ & P-value \\
\hline Age (years) & $55.767 \pm 7.001$ & $52.700 \pm 7.778$ & $52.523 \pm 7.571$ & 0.193 \\
\hline BMI (Kg|m ) & $27.530 \pm 2.613$ & $25.265 \pm 3.127$ & $25.835 \pm 2.799$ & $\mathbf{0 . 0 0 9}$ \\
\hline SBP (mmHg) & $124.689 \pm 7.303$ & $123.00 \pm 9.154$ & $125.003 \pm 5.130$ & 0.588 \\
\hline DBP (mmHg) & $77.667 \pm 6.261$ & $76.500 \pm 6.309$ & $78.002 \pm 6.959$ & 0.666 \\
\hline FBS (mg|dl) & $198.033 \pm 32.762$ & $95.533 \pm 9.853$ & $87.550 \pm 9.035$ & $<\mathbf{0 . 0 0 1}$ \\
\hline 2hr PP (mgldl) & $258.076 \pm 39.253$ & $113.534 \pm 10.441$ & $107.150 \pm 4.196$ & $<\mathbf{0 . 0 0 1}$ \\
\hline HbA1C (\%) & $8.991 \pm 0.991$ & $5.861 \pm 0.637$ & $4.941 \pm 0.472$ & $<\mathbf{0 . 0 0 1}$ \\
\hline Cholesterol (mgldl) & $215.733 \pm 49.228$ & $184.103 \pm 14.162$ & $146.602 \pm 25.527$ & $<\mathbf{0 . 0 0 1}$ \\
\hline TG (mg|dl) & $210.503 \pm 48.373$ & $152.803 \pm 17.385$ & $127.503 \pm 31.808$ & $<\mathbf{0 . 0 0 1}$ \\
\hline LDL (mgldl) & $137.843 \pm 20.765$ & $144.001 \pm 13.622$ & $132.250 \pm 8.451$ & $\mathbf{0 . 0 3 9}$ \\
\hline HDL (mgld) & $42.004 \pm 6.335$ & $46.967 \pm 3.882$ & $45.050 \pm 3.942$ & $\mathbf{0 . 1 2 9}$ \\
\hline F. Insulin (uIU/ml) & $36.751 \pm 2.556$ & 27.1534 .482 & $13.501 \pm 3.323$ & $<\mathbf{0 . 0 0 1}$ \\
\hline HOMA IR & $17.502 \pm 4.537$ & $7.136 \pm 1.413$ & $2.869 \pm 0.15$ & $<\mathbf{0 . 0 0 1}$ \\
\hline
\end{tabular}

Comparing serum interleukin one beta (IL-1 $\beta$ ) among the studied groups showed a significant difference among the 3 groups (Table 2).

Table (2): Comparison between cases and controls regarding Interleukin $1 \beta(\mathrm{pg} / \mathrm{ml})$

\begin{tabular}{|c|c|c|}
\hline Groups & IL-1B (pg/ml) & \multirow{2}{*}{ P-value } \\
\cline { 2 - 2 } & Mean \pm SD & \\
\hline Uncontrolled diabetic (group 1) & $100.000 \pm 98.436$ & \\
\hline Controlled diabetic (group 2) & $22.433 \pm 21.286$ & $<0.001$ \\
\hline Control (group 3) & $12.705 \pm 9.091$ & \\
\hline
\end{tabular}

Concerning correlation of interleukin one beta (IL 1 ) with other data in diabetic studied cases (group 1 and group 2); there was significant positive correlation with fasting blood sugar (FBS), 2 hours post prandial (2 hrs PP), glycosylated Hemoglobin (HBA1C), triglycerides (TG) and HOMA IR and there was a negative correlation with high density lipoproteins (HDL) and there was no significant correlation with other parameters (Table 3). 
Table (3): Correlation between IL $1 \beta$ and all other parameters in the studied group 1 and group 2 cases

\begin{tabular}{|c|c|c|c|c|}
\hline \multicolumn{5}{|c|}{ Correlations } \\
\hline & \multicolumn{4}{|c|}{ IL-1B } \\
\hline & \multicolumn{2}{|c|}{$\begin{array}{c}\text { Uncontrolled diabetics } \\
\text { (Group 1) }\end{array}$} & \multicolumn{2}{|c|}{$\begin{array}{l}\text { Controlled diabetics } \\
\text { (Group 2) }\end{array}$} \\
\hline & $\mathbf{r}$ & P-value & $\mathbf{r}$ & P-value \\
\hline Age (years) & 0.105 & 0.582 & 0.086 & 0.652 \\
\hline SBP (mmHg) & 0.125 & 0.511 & -0.025 & 0.897 \\
\hline DBP (mmHg) & 0.330 & 0.075 & 0.055 & 0.772 \\
\hline BMI $\left(\mathrm{Kglm}^{2}\right)$ & 0.091 & 0.632 & 0.141 & 0.456 \\
\hline FBS (mgldl) & 0.449 & 0.013 & 0.280 & 0.135 \\
\hline 2hr PP (mgldl) & 0.399 & 0.029 & 0.229 & 0.223 \\
\hline HbA1C (\%) & 0.272 & 0.146 & -0.118 & 0.534 \\
\hline Cholesterol (mgldl) & -0.047 & 0.805 & -0.051 & 0.788 \\
\hline TG (mgldl) & 0.127 & 0.504 & 0.080 & 0.674 \\
\hline LDL (mgldl) & -0.152 & 0.422 & -0.065 & 0.732 \\
\hline HDL (mgldl) & -0.211 & 0.264 & 0.022 & 0.909 \\
\hline F. Insulin (uIU/ml) & -0.298 & 0.110 & -0.043 & 0.822 \\
\hline HOMA IR & -0.151 & 0.425 & 0.011 & 0.952 \\
\hline
\end{tabular}

\section{DISCUSSION}

In present study, we found serum IL- $1 \beta$ levels were significantly higher in the type 2 diabetic patients than in the healthy control subjects. Also, we found that IL$1 \beta$ concentrations were significantly higher in uncontrolled diabetic patients than in controlled diabetic patients.

And there was a positive correlation between serum IL-1 $\beta$ concentrations and glycemic profile (FBS, 2 hrs PP and HBA1C) in diabetics generally. Additionally a significant positive correlation was found between serum IL-1 $\beta$ concentrations and glycemic control in uncontrolled diabetics over last 6 months, than in controlled diabetic patients group.

These results are consistent with Eizadi et al. ${ }^{(8)}$ who measured serum Il-1 $\beta$ concentrations, in 30 type 2 diabetic men patients and 36 healthy subjects matched for BMI, serum Il-1 $\beta$ concentrations were significantly higher in the type 2 diabetics than in the control group.

In the study conducted by Mirza et al. ${ }^{(9)}$ measuring inflammatory markers; cytokines (IL-6, TNF- $\alpha$, IL-1 $\beta$, IL-8) and adipokines (adiponectin, resistin and leptin) among 367 obese and over-weighted Mexican Americans, no significant correlation was found with serum Il-1 $\beta$ concentrations. But this can be explained by low number of diabetic patients among studied population (63 patients $29.7 \%$ ). Also it can be explained by ethnic differences since, and according to the study, diabetic Mexican Americans have lower levels of leptin than other ethnics.

Also, Schumann et al. ${ }^{(10)}$ experimental studies demonstrated that low concentration of IL- $1 \beta$ stimulates insulin release and proliferation in rat and human islets, which is against our study results but this can be explained by the use of different animal models of islets cells and that low concentrations of IL $1 \beta$ don't have deleterious effects on $\beta$ cells and that was shown later on by Maedler et al. ${ }^{(11)}$.

Our study results are also consistent with results from experimental studies done on mice by Maedler $\boldsymbol{e t}$ al. ${ }^{(12)}$ by exposing mice islet cells to increasing levels of IL $1 \beta$ and the results showed that high concentrations of IL- $1 \beta$ inhibits $\beta$-cell proliferation and exposure to 2 and $5 \mathrm{ng} / \mathrm{ml} \mathrm{IL-1} \beta$ increased the apoptosis rate by $2.3-$ and 3.6-fold. Whereas, low concentrations of IL-1 $\beta$ induced $\beta$-cell proliferation and had anti-apoptotic effect on islet cells. Exposure to $0.02 \mathrm{ng} / \mathrm{ml} \mathrm{IL-1 \beta}$ induced a two fold increase in $\beta$-cell proliferation compared with controls.

This also agrees with results in our study. In controlled diabetic patients, there were much lower levels of IL- $1 \beta$ concentrations than recently uncontrolled diabetics, which proves that beta cells destruction and hence development of diabetes is related to levels of IL- $\beta$. Also it shows that IL- $\beta$ acts also on beta cells not just peripheral tissues to induce insulin resistance and diabetes.

Hence, No significant positive correlation between serum IL- $1 \beta$ concentrations and glycemic control was found in controlled diabetic patients and even serum IL$1 \beta$ concentrations were lower.

This can be explained by the inflammatory nature of beta cells destruction in development of diabetes. Many studies have been conducted in order to develop the relationship between various inflammatory mediators and type 2 diabetes mellitus (DM), and have found abnormally high levels of various cytokines, plasminogen activator inhibitor, chemokines, acute phase proteins (such as CRP) in type 2 diabetic patients concluding that high circulating levels of IL-1 $\beta$, IL-6, 
and CRP can be the main predictive indicators for progression of type $2 \mathrm{DM}^{(\mathbf{1 3})}$.

Many studies also reported the role of IL- $1 \beta$ in beta cell apoptosis and chronic inflammation; it is reported that increased secretion of IL- $1 \beta$ have been linked not only to various autoimmune and auto-inflammatory diseases, but also to metabolic dysregulation ${ }^{(14)}$ and a disturbance in its secretion is associated with type II diabetic and impaired beta cell function ${ }^{(\mathbf{1 5}, 16)}$. IL-1 $\beta$, rather than being immediately cytotoxic, may cause tissue inflammation in type 2 diabetes, affecting both beta cell functional mass and insulin sensitivity ${ }^{(17)}$. In addition to impaired insulin secretion, IL-1 $\beta$ was found to induce $\beta$-cell death, which was potentiated by TNF$\alpha^{(16)}$.

The effects of IL-1 $\beta$ on $\beta$-cells of pancreas can be also demonstrated by the clinical trials using IL $1 \beta$ antagonist (Anakinra); According to the findings of a study by Dinarello ${ }^{\left({ }^{(18)}\right.}$, suppressing IL-1beta-mediated inflammation in the islet microenvironment by blocking its receptor with anakinra or neutralising anti-IL-1beta antibodies is sufficient for correcting dysfunctional beta-cell insulin production in type 2 diabetes, including the possibility that suppression of IL-1beta-mediated inflammation in the islet microenvironment allows for regeneration.

Larsen et al. ${ }^{(19)}$ conducted a double-blind, parallelgroup trial involving 70 patients with type 2 diabetes, 34 patients were randomly assigned to receive $100 \mathrm{mg}$ of anakinra (a recombinant human interleukin-1receptor antagonist) subcutaneously once daily for 13 weeks and 36 patients to receive placebo at baseline and at 13 weeks. At 13 weeks, in the anakinra group, the glycated hemoglobin level was 0.46 percentage point lower than in the placebo group $(\mathrm{P}=0.03)$; C-peptide secretion was enhanced $(\mathrm{P}=0.05)$, and there were reductions in the ratio of pro-insulin to insulin $(\mathrm{P}=0.005)$ and in levels of interleukin-6 $(\mathrm{P}<0.001)$ and $\mathrm{C}$-reactive protein $(\mathrm{P}=0.002)$. And they concluded that the blockade of interleukin-1 with anakinra improved glycemia and beta-cell secretory function and reduced markers of systemic inflammation ${ }^{(19)}$.

As regards fasting insulin, our study shows a fasting insulin higher in group of recently uncontrolled diabetics than in controlled diabetic patients and controls. There was also a weak negative correlation between IL $1 \beta$ and fasting insulin among recently uncontrolled diabetic patients.

This is consistent with results of study by Eizadi $\boldsymbol{e t}$ al. ${ }^{(8)}$ which found also a negative correlation between IL1 $\beta$ and fasting insulin among diabetic obese patients that supports the role of IL $1 \beta$ in insulin secretion of pancreatic beta cells.

However, the study by Eizadi et al. ${ }^{(8)}$ also showed lower serum insulin in diabetic patients than those of non-diabetics, this can be explained by: In our study, all patients were kept on sulphonylureas as oral hypoglycemic medication, which directly stimulates $\beta$ cells to secrete insulin; and the negative correlation between IL $1 \beta$ and fasting insulin appears only in recently uncontrolled diabetics. And this can be explained by gradual destruction and decrease in $\beta$ cell function by chronic inflammation mediated by IL $1 \beta$.

Also as regards HOMA IR our study showed that HOMA IR level higher in uncontrolled diabetics than controlled diabetics or control group. There was also positive correlation between IL $1 \beta$ and HOMA IR in diabetic population as a whole.

This is consistent to results from studies done by Ahmadi et al. ${ }^{(20)}$ and Eizadi et al. ${ }^{(8)}$ who studied serum IL1 $\beta$ levels among obese diabetic patients and normal subjects, and showed higher fasting blood glucose and insulin resistance in diabetic patients compared to non-diabetic subjects, while beta cell function in these patients was significantly lower than those without diabetes.

However and again, study by Mirza et al. ${ }^{\left({ }^{9}\right)}$ showed no significant correlation between IL $1 \beta$ and HOMA IR. But this can also be explained by low number of diabetic patients among studied population (63 patients $29.7 \%$ ) among the study. Also can be explained by ethnic differences since, according to the study, diabetic Mexican Americans have relatively lower levels of leptin than other ethnics.

As regards cholesterol, the present study showed a significant difference between group of uncontrolled diabetics and controlled diabetics compared to the group of controls.

As regards triglycerides level, there was also significant difference between uncontrolled diabetics and controlled diabetics to the group of controls.

A significant positive correlation was found between serum IL $1 \beta$ concentration and serum triglycerides (TG) in diabetic studied cases (group 1 plus 2), whereas a significant negative correlation was found with high density lipoproteins (HDL).

In those with visceral obesity, metabolic syndrome, or type 2 diabetes, hypertriglyceridemia is a prevalent lipid abnormality. Hypertriglyceridemia is related with an elevated cardiovascular risk when it occurs in conjunction with low HDL levels and atherogenic tiny dense LDL particles. Insulin resistance is a common underlying characteristic, and increased peripheral lipolysis resulting in increased free fatty acid (FFA) transport to the liver ${ }^{(21)}$.

\section{CONCLUSION}

In conclusion our study found that serum IL-1 $\beta$ significantly increased in recently uncontrolled diabetics than controlled diabetics and normal subjects and also serum IL-1 $\beta$ was positively correlated with glycemic levels and control. These results suggest possible role of IL- $1 \beta$ in pathogenesis of type 2 diabetes. So, further studies are needed to clarify the possible role of other cytokines in the pathogenesis of type 2 DM. Also, further studies and trials regarding the use of interleukin one beta antagonist (Anakinra) in treatment and stopping disease progression in type $2 \mathrm{DM}$. 
Financial support and sponsorship: Nil.

Conflict of interest: Nil.

\section{REFERENCES}

1. Donath M, Storling J, Berchtold L et al. (2008): Cytokines and beta-cell biology: from concept to clinical translation. Endocr Rev., 29: 334-350.

2. Maedler K, Sergeev P, Ris F et al. (2002): Glucoseinduced beta cell production of IL-1beta contributes to glucotoxicity in human pancreatic islets. J Clin Invest., 110: 851-860.

3. Steffes M, Sibley S, Jackson M et al. (2003): Beta cell function and the development of diabetes-related complications in the diabetes control and complications trial. Diabetes Care, 26: 832-8

4. Festa A, D'Agostino R, Howard G et al. (2000): Chronic subclinical inflammation as part of the insulin resistance syndrome: the Insulin Resistance Atherosclerosis Study (IRAS). Circulation, 102: 42-47.

5. Boni-Schnetzler M, Thorne J, Parnaud G et al. (2008): Increased interleukin (IL)-1b messenger ribonucleic acid expression in b-cells of individuals with type 2 diabetes and regulation of IL-1b in human islets by glucose and autostimulation. J Clin Endocrinol Metab., 93: 40654074.

6. Elouil H, Cardozo A, Eizirik D et al. (2005): High glucose and hydrogen peroxide increase c-Myc and haeme-oxygenase $1 \mathrm{mRNA}$ levels in rat pancreatic islets without activating NFkB. Diabetologia, 48: 496-505.

7. Maedler K, Dharmadhikari G, Schumann D et al. (2011): Interleukin-targeted therapy for metabolic syndrome and type 2 diabetes. Handb Exp Pharmacol., 11: 257-278.

8. Eizadi M, Kohandel M, Kasbparast J et al. (2011): Serum interleukin-1 beta plays an important role in insulin secretion in type II diabetic. International Journal of Biosciences, 3: 93-99.

9. Mirza M, Christine M, Perla M et al. (2011): Type 2Diabetes is associated with elevated levels of TNF-alpha, IL-6 and adiponectin and low levels of leptin in a population of Mexican American: A Cross-Sectional Study.J Ccyto., 11: 132-138.

10. Schumann D, Maedler K, Franklin I (2007): The Fas pathway is involved in $\beta$-cell secretory function. Proc Natl Acad Sci USA., 104: 2861 -6.

11. Maedler K, Dharmadhikari G, Schumann D et al. (2007): Interleukin-1 beta targeted therapy for type 2 diabetes. Expert Opin Biol Ther., 9 (9), 1177-88.

12. Maedler K, Schumann D, Sauter N (2006): Low concentration of interleukin-1 $\beta$ induces FLICEinhibitory protein-mediated $\beta$-cell proliferation in human pancreatic islets. Diabetes, 55: 2713 -22.

13. Haldar P, Brightling C, Hargadon B et al. (2009): Mepolizumab and exacerbations of refractory eosinophilic asthma. N Engl J Med., 360: 973-84.

14. Dinarello C, Arend W, Sims J et al. (2010): IL-1 family nomenclature. Nat Immunol., 11: 973-77.

15. Mandrup-Poulsen T, Bendtzen K, Nerup J (1998): Affinity-purified human interleukin $\mathrm{I}$ is cytotoxic to isolated islets of Langerhans. Diabetologia, 29: 63 -7.

16. Eizirik D (1988): Interleukin-1 induced impairment in pancreatic islet oxidative metabolism of glucose is potentiated by tumor necrosis factor. Acta Endocrinol (Copenh), 119: 321 -5.

17.Ehses J, Lacraz G, Giroix M (2009): IL-1 antagonism reduces hyperglycemia and tissue inflammation in the type 2 diabetic GK rat. Proceedings of the National Academy of Sciences of the United States of America, 106 (33): 13998-14003.

18. Dinarello C (2009): Immunological and inflammatory functions of the interleukin-1 family. Annu Rev Immunol., 27: 519 -50.

19.Larsen C, Faulenbach M, Vaag A et al. (2007): Interleukin-1-receptor antagonist in type 2 diabetes mellitus. N Engl J Med., 356(15): 1517-26.

20. Ahmadi P, Torabi M, AranArdabili A et al. (2012): Interleukin-1 beta is increased in presence of type 2 diabetes in addition to adiposity level. International Journal of Biosciences, 2: 1-7.

21. Carroll M, Lacher D, Sorlie P et al. (2005): Trends in serum lipids and lipoproteins of adults, 1960, 2002. JAMA., 294: 1773-1781. 